\title{
IBL4, A B cell line derived from an AIDS-related lymphoma, is a novel tumor stimulator and target for $\mathrm{Vy} 2 \mathrm{Vd} 2 \mathrm{~T}$ cell Andrew Hebbeler*, Jean-Saville Cummings, Cristiana Cairo and C David Pauza
}

Address: Institute of Human Virology, University of Maryland Biotechnology Institute, Baltimore, Maryland, 21201, USA

* Corresponding author

from 2006 International Meeting of The Institute of Human Virology

Baltimore, USA. |7-2I November, 2006

Published: 21 December 2006

Retrovirology 2006, 3(Suppl I):P24 doi:I0.I I86/I742-4690-3-SI-P24

(C) 2006 Hebbeler et al; licensee BioMed Central Ltd.

Vg2Vd2 T cells are the predominant peripheral blood subset of - T cells and recognize tumor cells in a TCR-dependent, MHC-unrestricted manner. Following HIV infection there is a rapid and targeted depletion of circulating, antitumor Vy2Vd2 T cells with concomitant increases in B cell lymphoma incidence. We hypothesized that the specific depletion of Vy2Vd2 T cells after HIV compromises an important tumor surveillance system and directly contributes to the increased incidence of $\mathrm{B}$ cell lymphoma observed in HIV-positive cohorts. To test this hypothesis we collected tumor cell lines derived from clinical cases of AIDS-related lymphoma and tested them for susceptibility to $\mathrm{Vy} 2 \mathrm{Vd} 2$ cytotoxicity and ability to stimulate Vy2Vd2 T cell proliferation from PBMC in vitro. Several tumor cell lines including Daudi, KSY1 and IBL4 were recognized and lysed by polyclonal $\mathrm{Vy} 2 \mathrm{Vd} 2 \mathrm{~T}$ cell effectors in a dosedependent manner. We screened several irradiated AIDSderived tumor lines in vitro for the capacity to stimulate Vy2Vd2 T cells and identified IBL4 as a novel tumor stimulator for the $\mathrm{Vy} 2 \mathrm{Vd} 2$ subset that skewed the Vy2 repertoire toward longer chain lengths without affecting the overall distribution of $\mathrm{Vy} 2$ chain lengths and without obvious tumor-specific CDR3 sequences commonality among responding blood donors. These data provide important insight into tumor recognition by $\mathrm{Vy} 2 \mathrm{Vd} 2 \mathrm{~T}$ cells and justify chemotherapeutic approaches using alkylphosphate stimulation to boost the frequency and tumor effector function of circulating $\mathrm{Vy} 2 \mathrm{Vd} 2 \mathrm{lym}-$ phocytes. 